\title{
A new Middle Cambrian stem-group echinoderm from Spain: Palaeobiological implications of a highly asymmetric cinctan
}

\author{
Samuel Zamora and Andrew B. Smith \\ Acta Palaeontologica Polonica 53 (2), 2008: 207-220 doi:http://dx.doi.org/10.4202/app.2008.0204
}

A new exquisitely preserved stem group echinoderm (cinctan), Lignanicystis barriosensis gen. et sp. nov., is described from the Middle Cambrian of Los Barrios de Luna, North Spain. This displays a unique asymmetrical body plan with ventral projecting nodes that raised the lower surface above the substratum. There are four openings through the body wall: mouth, anus, atrium, and an aligned row of sutural pores of uncertain function. Unlike other cinctans, Lignanicystis has a strongly asymmetrical shape convergent with that of some cornute carpoids. Like cornutes, the test is also elevated above the substratum to allow water flow beneath the theca. In both cases this is probably an adaptation to life in higher water flow regimes.

Key words: Echinodermata, Homostelea, carpoids, functional morphology, Cambrian, Spain

Samuel Zamora [samuel@unizar.es], Área y Museo de Paleontología, Departamento de Ciencias de la Tierra, Universidad de Zaragoza, E-50009 Zaragoza, Spain;

Andrew B. Smith [a.smith@nhm.ac.uk], Department of Palaeontology, The Natural History Museum, Cromwell Road, London SW7 5BD, UK.

This is an open-access article distributed under the terms of the Creative Commons Attribution License (for details please see creativecommons.org), which permits unrestricted use, distribution, and reproduction in any medium, provided the original author and source are credited.

FoF Full text $(1,511.3 \mathrm{kB})$ 